\title{
The epicardial electrogram: a quantitative assessment during balloon angioplasty incorporating monophasic action potential recordings
}

\author{
PETER TAGGART, PETER SUTTON, * ROY JOHN, ROGER HAYWARD, \\ HOWARD SWANTON \\ From the Department of Cardiology, The Middlesex Hospital, London and ${ }^{\star}$ Department of Physiology, \\ University College and Middlesex Hospital School of Medicine, London
}

SUMMARY An electrogram was recorded from the angioplasty catheter guide wire when coronary blood flow was interrupted in 20 patients undergoing percutaneous transluminal coronary angioplasty. Monophasic action potentials were recorded from the right ventricular septum together with the routine electrocardiogram. The patients were studied during angioplasty for lesions in the left anterior descending (12), circumflex (3), and right coronary arteries (6). ST elevation in the electrogram recorded in the left anterior descending and circumflex systems was usually more obvious than that in the electrocardiogram. Signals obtained from the right coronary artery were of very low amplitude and registered only minimal ST changes. The ST elevation developed in the electrogram during insertion of the catheter before inflation of the balloon in 11 of the 15 patients undergoing angioplasty of the left system. In eight of the patients showing preinflation ST elevation the ST shift lessened after successive inflations. Monophasic action potential recordings were obtained during 45 balloon inflations in 19 patients. In those patients undergoing angioplasty for lesions of the circumflex coronary artery the monophasic action potential showed no change during balloon inflation. In patients undergoing angioplasty for the right coronary artery the mean normalised duration at 60 seconds' occlusion was $99.6(1.5) \%$ of control. Of a total of 25 occlusions in the patients undergoing angioplasty for the left anterior descending coronary artery 19 showed shortening of $<5 \%$, five showed shortening between 5 and $10 \%$, and one showed a shortening of $16.4 \%$ in the monophasic action potential. The QT interval was satisfactorily measured in the electrogram during 36 balloon inflations, and in 24 of these it was also measured in the electrocardiogram. QT changes in the electrogram tended to be the opposite of those in the electrocardiogram. When changes in $R R$ interval were minimal ( $<20 \mathrm{~ms}$ ) during the balloon inflation 14 of 17 electrograms showed QT prolongation but only one of 12 electrocardiograms showed prolongation. Conversely one of 17 electrograms showed shortening compared with eight of 12 electrocardiograms. There was angiographic evidence of the development of collaterals in six of 15 patients undergoing angioplasty of the left system. ST segment elevation in both the electrogram and electrocardiogram was less pronounced in these patients than in those without evidence of the development of collaterals.

ST segment changes recorded from the angioplasty guide wire provide a more sensitive index of ischaemia than the surface 12 lead electrocardiogram, and a fall in ST segments on balloon deflation is a prognostic index of a good angiographic result in the left anterior descending and circumflex arteries, but not in the right coronary artery.

Requests for reprints to Dr Peter Taggart, Department of Cardiology, The Middlesex Hospital, Mortimer Street, London W1N 8AA. 
Ever since Einthoven either did or did not invent the string galvanometer ${ }^{1}$ the electrocardiogram has played a fundamental role $^{2}$ in the detection of myocardial ischaemia. Although a mainstay for on line monitoring it may be relatively insensitive to the early phase of ischaemia. The very earliest electrophysiological changes of ischaemia tend to be local to the causative lesion. ${ }^{3}$ The initial area affected therefore tends to be small. Solid angle theory predicts that an electrode for recording an electrocardiogram would need to be placed very close to the lesion in order to identify any ischaemic changes. ${ }^{45}$ This is not usually possible and the ischaemic changes that are eventually picked up by the routine electrocardiogram reflect more progressive and extensive ischaemic changes; the original local change being silent in the electrocardiogram.

The electrocardiogram is routinely used to monitor patients during percutaneous transluminal coronary angioplasty. ST segment changes are often seen during the sudden transient interruption of coronary artery blood flow when the balloon is inflated. The accuracy with which this measures the degree of ischaemia is, however, questionable. As indicated above, a recording site closer to the myocardium would be expected to register earlier changes.

The monophasic action potential recorded directly from the myocardium has been shown to provide a highly sensitive index of ischaemia. ${ }^{67}$ Monophasic action potentials recorded during angioplasty from the left ventricular endocardium in the potentially ischaemic zone registered ischaemic changes in advance of the electrocardiogram in selected patients. ${ }^{8}$ However, depending on the site of the lesion and the individual anatomy it may not always be technically possible to gain access to the centre of a potentially ischaemic zone with a catheter electrode for measuring an endocardial monophasic action potential. ${ }^{9}$

The tip of the guide wire used for angioplasty, however, lies close to the lesion. It has been shown that electrical signals may be transmitted via this wire thus enabling an epicardial electrogram to be recorded. ${ }^{9-11}$ An electrogram recorded by this means has the advantage of recording near the myocardium from the territory whose native circulation is the artery undergoing angioplasty.

ST changes in the intracoronary electrogram occur in most patients during angioplasty and are generally more obvious than in the electrocardiogram. ${ }^{11} 12$ In addition, preliminary results showed that assessment of ST segment changes in the electrogram recorded from the angioplasty guide wire during periods of balloon deflation between successive occlusions provided evidence of a good angiographic result when any initial ST elevation had subsequently been reduced by $50 \%$ at the end of the procedure. ${ }^{12}$

However, it is likely that any ST segment changes in the electrogram will be influenced by the development of collaterals and the dynamic behaviour of local collateral vessels in response to the ischaemic challenge and intermittent reperfusion. Furthermore, the closeness of the recording electrode to the myocardium would be expected to make it especially sensitive to the local dispersion of action potential amplitude and duration that is characteristic of early ischaemia. This may well, therefore, result in differences in the manifestation of early ischaemic change such as the ST segment and QT interval in the electrogram and the electrocardiogram. We studied simultaneous electrographic and electrocardiographic changes in the ST segment and QT interval during routine angioplasty and have related these changes to angiographic evidence of the development of collaterals.

\section{Patients and methods}

Recordings were made of the epicardial electrogram, right ventricular endocardial monophasic action potential, and the routine electrocardiogram in patients undergoing angioplasty for the relief of angina.

\section{PATIENTS}

Twenty patients were selected at random from the waiting list (table 1). Twelve were undergoing angioplasty of the left anterior descending coronary artery, three of the circumflex coronary artery, and six of the right coronary artery. One patient underwent angioplasty of both a left anterior descending and right coronary artery lesion. Table 1 gives the details of individual patients including the site and severity of the lesions. The hospital ethics committee gave approval for this study.

\section{EPICARDIAL ELECTROGRAM}

We used the angioplasty catheter guide wire as the exploring electrode to record an epicardial electrogram from within the lumen of the coronary artery. The reference electrode was positioned close to the entry point in the femoral artery. When the balloon of the dilatation catheter was positioned across the stenotic segment of the artery, the guide wire protruded about $5 \mathrm{~cm}$ beyond the tip of the dilatation catheter. The proximal end of the guide wire was scraped with a scalpel to remove the Teflon coating to ensure good electrical continuity. 
Table 1 Details on the 20 patients in the study

\begin{tabular}{|c|c|c|c|c|c|c|}
\hline $\begin{array}{l}\text { Patient } \\
\text { no }\end{array}$ & Sex & Age & Vessel & Site & Collaterals & Result \\
\hline 1 & $\mathbf{M}$ & 53 & LAD & Proximal LAD at diagonal origin & None & $\begin{array}{l}\text { Moderate } 30-50 \% \text { residual } \\
\text { stenosis }\end{array}$ \\
\hline $\begin{array}{l}2 \\
3 \\
4\end{array}$ & $\begin{array}{l}\mathbf{M} \\
\mathbf{M} \\
\mathbf{M}\end{array}$ & $\begin{array}{l}46 \\
62 \\
61\end{array}$ & $\begin{array}{l}\text { LAD } \\
\text { LAD } \\
\text { LAD }\end{array}$ & $\begin{array}{l}\text { Proximal LAD distal to } 1 \text { st diagonal } \\
\text { Distal to } 1 \text { st septal/diagonal } \\
\text { Distal to } 1 \text { st septal proximal lesion }\end{array}$ & $\begin{array}{l}\text { Minimal if any to distal septum } \\
\text { None } \\
\text { None }\end{array}$ & $\begin{array}{l}\text { Moderate } 30 \% \text { residual stenosis } \\
\text { Moderate result dissection flap } \\
\text { Good on proximal but distal } \\
\text { remain }\end{array}$ \\
\hline 5 & $\mathbf{M}$ & 48 & LAD & Proximal to 1st septal & Yes & $\begin{array}{l}\text { Moderate residual } 40 \% \text { stenosis } \\
\text { with dissection }\end{array}$ \\
\hline $\begin{array}{r}6 \\
7 \\
8 \\
9 \\
10\end{array}$ & $\begin{array}{l}\mathbf{F} \\
\mathbf{M} \\
\mathbf{M} \\
\mathbf{M} \\
\mathbf{M}\end{array}$ & $\begin{array}{l}37 \\
69 \\
65 \\
58 \\
57\end{array}$ & $\begin{array}{l}\text { LAD } \\
\text { LAD } \\
\text { LAD } \\
\text { LAD } \\
\text { LAD }\end{array}$ & $\begin{array}{l}\text { Proximal to } 1 \text { st septal } \\
\text { Lesion at } 1 \text { st septal } \\
\text { Proximal to diagonal distal to } 1 \text { st septal } \\
\text { Distal to } 1 \text { st septal } \\
\text { Distal to } 1 \text { st septal origin of diagonal }\end{array}$ & $\begin{array}{l}\text { Yes } \\
\text { None } \\
\text { None } \\
\text { To septum posterior } \\
\text { Very sparse distal on septum } \\
\text { from RCA }\end{array}$ & $\begin{array}{l}\text { Good } \\
\text { Moderate } 30 \% \text { residual stenosis } \\
\text { Good } \\
\text { Good } \\
\text { Good }\end{array}$ \\
\hline $\begin{array}{l}11 \mathrm{a} \\
11 \mathrm{~b}\end{array}$ & $\mathbf{M}$ & 53 & $\begin{array}{l}\text { LAD } \\
\text { RCA }\end{array}$ & $\begin{array}{l}\text { Proximal to 1st septal } \\
\text { Mid RCA proximal to margin }\end{array}$ & Yes & $\begin{array}{l}\text { Good } \\
\text { Good }\end{array}$ \\
\hline 12 & $\mathbf{M}$ & 46 & $\mathbf{L A D}$ & $\begin{array}{l}\text { Distal to } 1 \text { st septal and proximal to } \\
\text { diagonal }\end{array}$ & Yes (late) & Good \\
\hline 13 & $\mathbf{M}$ & 42 & $\begin{array}{l}\text { Cx } \\
\text { graft }\end{array}$ & Mid Cx graft & None & Good \\
\hline $\begin{array}{l}14 \\
15\end{array}$ & $\begin{array}{l}\mathbf{M} \\
\mathbf{M}\end{array}$ & $\begin{array}{l}67 \\
56\end{array}$ & Cx & $\begin{array}{l}\text { Large obtuse marginal } \\
\text { Origin of } 1 \text { st obtuse marginal of } \mathrm{Cx}\end{array}$ & $\begin{array}{l}\text { None } \\
\text { None to } \mathrm{LV} \text { surface collaterals } \\
\text { to inferior surface in RCA } \\
\text { territory }\end{array}$ & $\begin{array}{l}\text { Good } \\
\text { Good }\end{array}$ \\
\hline $\begin{array}{l}16 \\
17 \\
18 \\
19 \\
20\end{array}$ & $\begin{array}{l}\mathbf{M} \\
\mathbf{M} \\
\mathbf{M} \\
\mathbf{M}\end{array}$ & $\begin{array}{l}62 \\
51 \\
57 \\
61 \\
70\end{array}$ & $\begin{array}{l}\mathbf{R C A} \\
\mathbf{R C A} \\
\mathbf{R C A} \\
\mathbf{R C A} \\
\mathbf{R C A}\end{array}$ & $\begin{array}{l}\text { Proximal to RV branch } \\
\text { Proximal to RV branch } \\
\text { Proximal to RV branch } \\
\text { Mid RCA past RV branch } \\
\text { Proximal to RV branch }\end{array}$ & $\begin{array}{l}\text { None } \\
\text { None } \\
\text { Yes } \\
\text { None } \\
\text { None }\end{array}$ & $\begin{array}{l}\text { Good } \\
\text { Good } \\
\text { Good } \\
\text { Good with dissection flap } \\
\text { Good }\end{array}$ \\
\hline
\end{tabular}

LAD, left anterior descending; $\mathrm{Cx}$, circumflex; $\mathrm{RCA}$, right coronary artery; $\mathrm{RV}$, right ventricle.

\section{ENDOCARDIAL MONOPHASIC ACTION}

\section{POTENTIALS}

Monophasic action potentials were recorded with a bipolar pressure contact silver/silver chloride catheter electrode (size 7 French) made to our specifications (Cordis). The exploring electrode $\left(1.0 \mathrm{~mm}^{2}\right)$ was situated at the tip. The reference electrode ( 1.0 $\mathrm{mm}^{2}$ ) was situated $5 \mathrm{~mm}$ back from the tip and was flush with the wall of the catheter. Gentle apposition of the tip electrode to the endocardium results in a monophasic action potential signal of usually $20-40$ mV amplitude.

\section{ROUTINE ELECTROCARDIOGRAM}

The lead monitored as part of the routine procedure was recorded. The lead chosen was the one considered to be the most appropriate to the site of the lesion undergoing angioplasty - that is lead III for the right coronary artery; V5 for the left anterior descending coronary artery; and aVL, V5, or lead III for the circumflex, depending on which gave the best signal (see table 1).

\section{SIGNAL PROCESSING}

The electrogram and monophasic action potential signals were fed into Gould isolated preamplifiers (model 11-5407-58) to provide patient isolation and then into DC Gould universal amplifiers (model 134615-58). The amplifiers for the monophasic action potential and electrogram were set to give an outputo of $1 \mathrm{~V}$ for $40 \mathrm{mV}$ input with a frequency response ofö $300 \mathrm{~Hz}$. The signals were displayed on a Simonsen $\mathbb{2}$ and Weel monitor (Model MTS 102). The electro- $\overrightarrow{0}$ cardiogram was amplified. A Gould instruments 3 brush 220 pen recorder was used for hard copy? recordings of the electrogram, monophasic action potential, and routine electrocardiogram at a paper speed of $1,5,25$ or $125 \mathrm{~mm} / \mathrm{s}$ as appropriate. The monophasic action potential and electrogram record-7ings were calibrated with a direct current millivolt 3 source (Time Electronics model 4045).

\section{PROCEDURE}

All patients had had a coronary arteriogram with left ventricular angiogram via the right femoral artery byo the Judkins technique on a previous occasion. This was repeated immediately before angioplasty with ano Advanced Cardiovascular Systems incorporated French 9 shaft tip guiding catheter. After theN immediate pre-angioplasty coronary arteriogram, of monophasic action potential catheter was inserted via the right femoral vein and positioned on the right ventricular septum in an area that would be expectedes to be supplied at least in part by the artery under going angioplasty.

The angioplasty balloon catheter (usually a Simp-D son ultra-low profile balloon catheter, Advancedक Cardiovascular Systems, Incorporated), and guide 
wire (usually a 0.014 inch flexible steerable wire, USCI, CR Bard Incorporated) were advanced into the target artery. Once the guide wire had crossed the lesion, an electrogram signal was obtained from the wire. The dilatation catheter was then advanced across the stenosis. Recordings were then made of the electrogram, monophasic action potential, and routine electrocardiogram during successive balloon inflations. $U p$ to four successive balloon inflations were carried out for 60 seconds with 2-5 minutes interval between them during which time the catheter and guide wire remained in position. Atrial pacing was not used routinely but was established when necessary (two patients).

\section{STATISTICAL ANALYSIS}

ST segment shift in the electrogram and electrocardiogram was measured at $60 \mathrm{~ms}$ after the $\mathrm{J}$ point. These data were displayed and presented in millimetres rather than millivolts as these represent the changes normally seen by the operator and used to monitor the procedure. A millivolt scale is included.

The QT interval was measured only in those records where the end of the $T$ wave could be clearly defined. The QT measurements are presented (uncorrected for rate) with respective $R R$ intervals.

The duration of the monophasic action potential was measured at $90 \%$ repolarisation by drawing a tangent to the steepest part of the slope. These data were normalised to take account of differences in heart rate between patients.

The angiographic result was assessed as good or moderate by visual inspection at the time of the procedure. The result was classified as good when the residual stenosis was $<20 \%$ and moderate when the residual stenosis was between $20 \%$ and $50 \%$.

\section{Results}

\section{ST SEGMENT}

An ST segment shift in the epicardial electrogram was invariably upwards-that is ST elevation. In the electrocardiogram, ST shift was either up or downthat is elevation or depression depending upon the orientation of the lead position.

Most patients undergoing angioplasty of the left anterior descending or circumflex coronary arteries showed ST changes in the epicardial electrogram during the procedure (fig 1). These ST changes were usually more conspicuous than in the routine electrocardiogram and sometimes spectacular. In two of 13 patients ST changes were consistently seen in the electrogram when no ST shift occurred in the electrocardiogram. In two of the 13 patients ST changes developed in the electrocardiogram in the absence of either any change (patient 6 ) or minimal change (patient 13) in the electrogram. The elec-

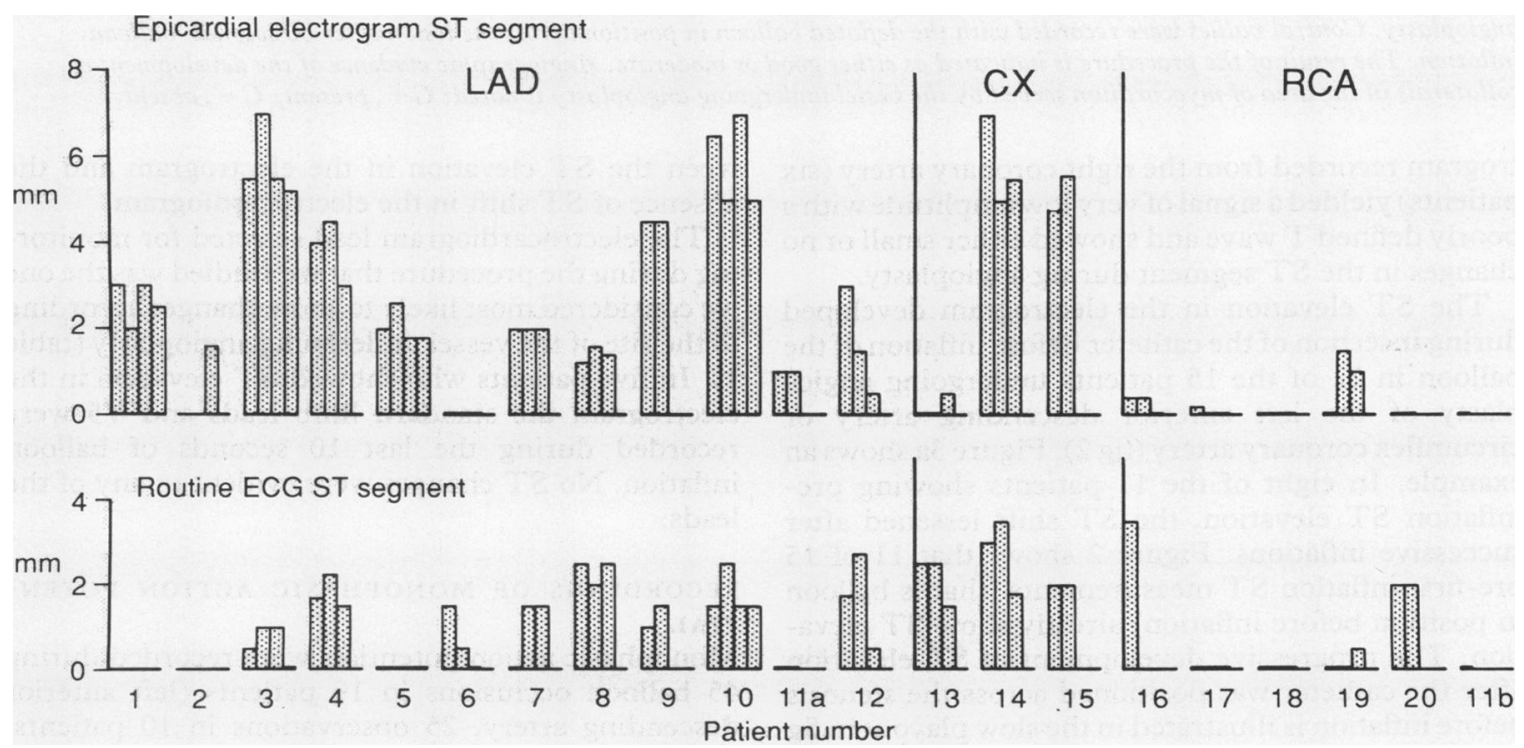

Fig 1 Histogram showing $S T$ segment shift in millimetres in the epicardial electrogram (top) and routine electrocardiogram (bottom) after 60 seconds of balloon occlusion (up to four balloon occlusions per patient) of the left anterior descending (LAD) circumflex $(C x)$, and right coronary artery $(R C A)$ during angioplasty. The $S T$ segment shift in the epicardial electrogram was invariably upwards. In the electrocardiogram ST shift was either up or down depending on the orientation of the lead position. 
Fig 2 Histogram showing ST segment elevation in millimetres in the epicardial electrogram during up to four balloon occlusions of the left anterior descending (patients 1-12) and the circumflex (patients 13-15) coronary artery during angioplasty. Control values were recorded with the deflated balloon in position across the lesion after 60 seconds' balloon inflation. The result of the procedure is indicated as either good or moderate. Angiographic evidence of the development of collaterals in the area of myocardium served by the vessel undergoing angioplasty is noted: $C+$, present; $C-$, absent.

trogram recorded from the right coronary artery (six patients) yielded a signal of very low amplitude with a poorly defined $T$ wave and showed either small or no changes in the ST segment during angioplasty.

The ST elevation in the electrogram developed during insertion of the catheter before inflation of the balloon in 11 of the 15 patients undergoing angioplasty of the left anterior descending artery or circumflex coronary artery (fig 2 ). Figure 3 a shows an example. In eight of the 11 patients showing preinflation ST elevation, the ST shift lessened after successive inflations. Figure 2 shows that 11 of 15 pre-first inflation ST measurements (that is balloon in position before inflation) already show ST elevation. The progressive development of ST elevation after the catheter was positioned across the stenosis before inflation is illustrated in the slow playout in fig 3a. Two successive balloon inflations of the same lesion are shown in figs $3 a$ and $3 b$, which show the progressive development of ST elevation during inflation and lessening of the ST elevation after balloon deflation. There is a striking contrast bet- ween the ST elevation in the electrogram and the absence of ST shift in the electrocardiogram.

The electrocardiogram lead selected for monitoring during the procedure that we studied was the one we considered most likely to show changes according to the site of the vessel undergoing angioplasty (table 1). In five patients who showed ST elevation in the electrogram the standard limb leads and V5 were 9 recorded during the last 10 seconds of balloon $D$ inflation. No ST changes were evident in any of the leads.

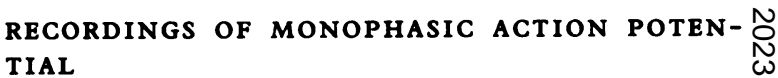

Monophasic action potentials were recorded during $\widetilde{\sigma}$ 45 balloon occlusions in 19 patients (left anterior 0

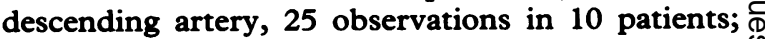
circumflex artery, eight observations in three $\stackrel{\mathcal{C}}{\rightarrow}$ patients; right coronary artery, 12 observations in six $T$ patients). In the patients undergoing angioplasty for $\stackrel{\vec{P}}{\overrightarrow{0}}$

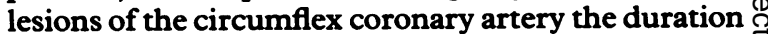
of the monophasic action potential duration showed $\stackrel{\mathbb{D}}{\Omega}$ 
(a)

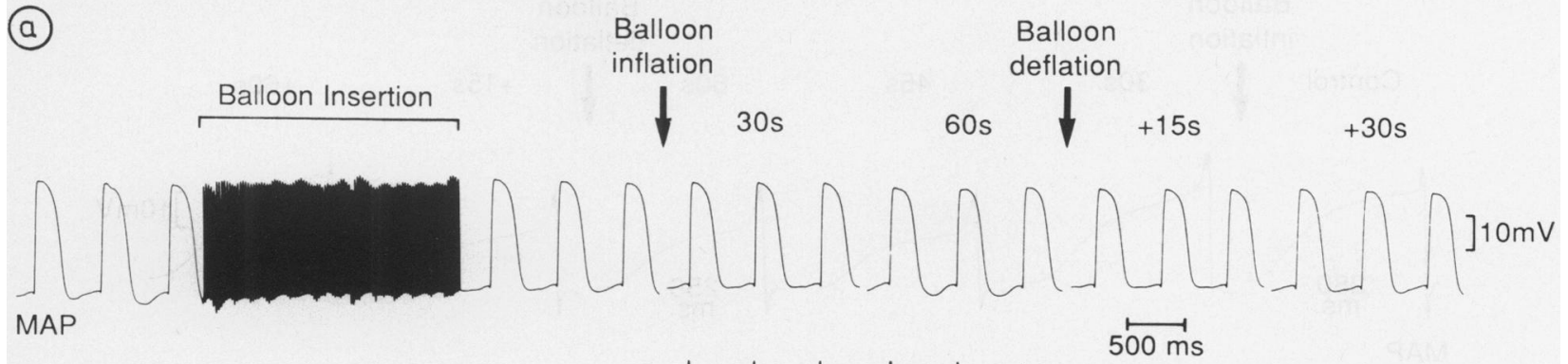

MAP

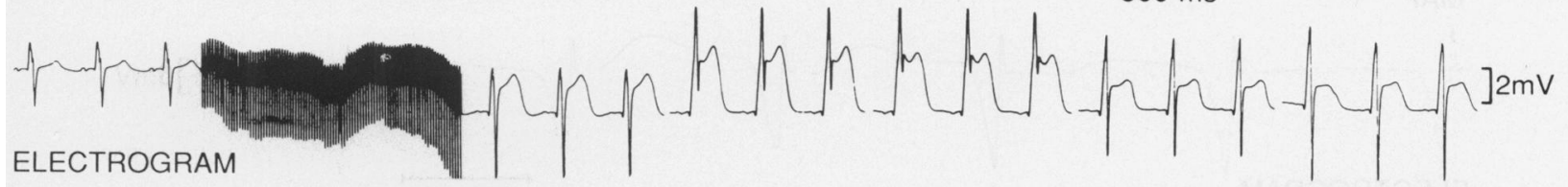

ECG

III

$60 \mathrm{~s}$

(b)

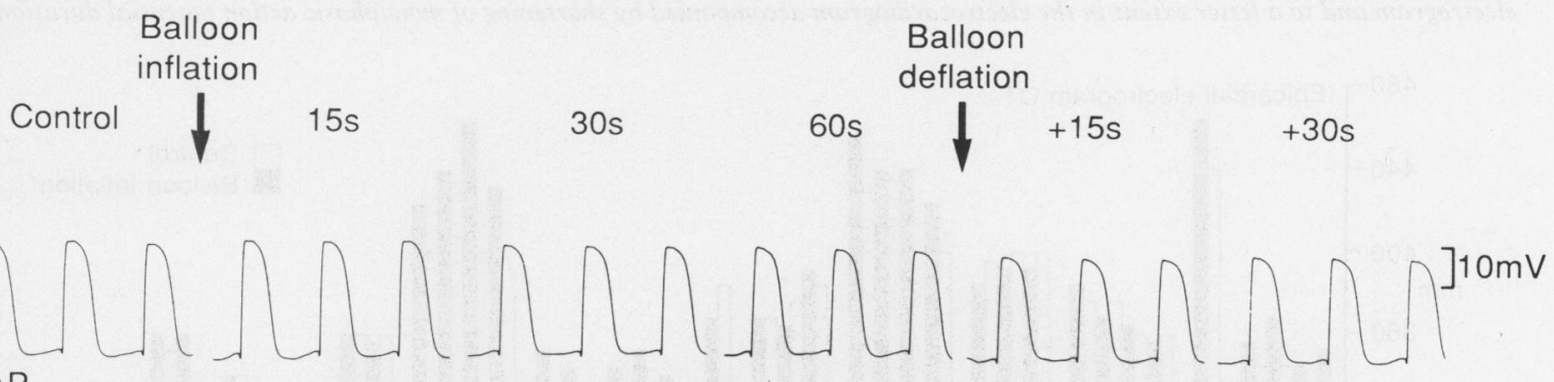

MAP

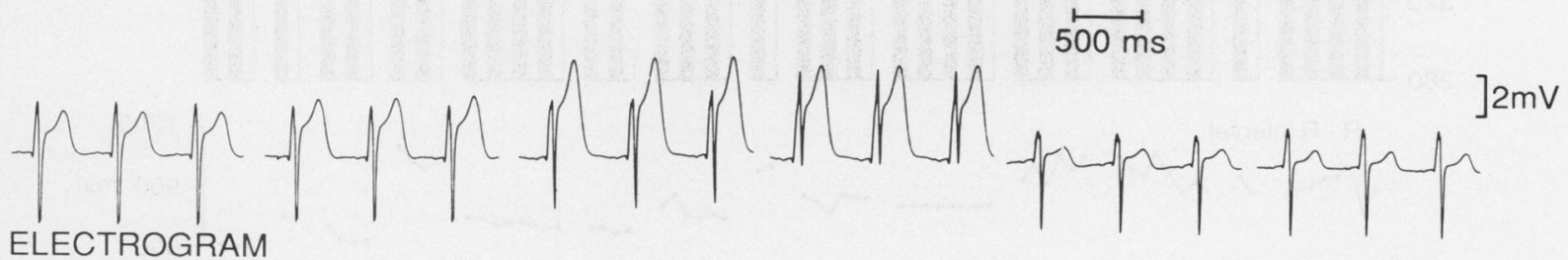

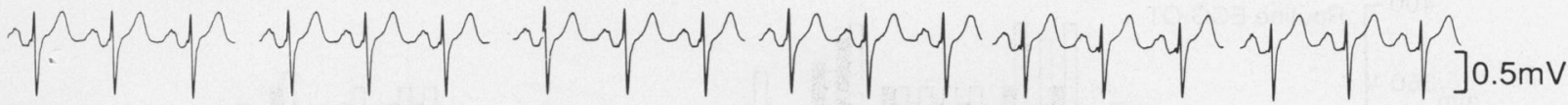

ECG

III

Fig 3 (a) Monophasic action potential (MAP), electrogram, and routine electrocardiogram (lead III) in a patient undergoing angioplasty of the circumflex coronary artery. During the 60 seconds after insertion of the deflated balloon there was progressive $S T$ elevation in the electrogram on the slow playout with little change in the electrocardiogram. ST elevation increased in the electrogram during the 60 second period of balloon inflation and decreased after deflation although some elevation persisted. The electrocardiogram remained unchanged throughout. No changes were seen in monophasic action potential (MAP) duration. (b) A second balloon inflation on the same patient performed after three minutes' rest. The $S T$ elevation in the electrogram again increased but this time it returned to the isoelectric line (with the balloon still in position) after deflation. The ST segment in the electrocardiogram (ECG) and monophasic action potential (MAP) duration were unchanged throughout. 
Fig 4 Monophasic action potential (MAP), electrogram, and electrocardiogram (V5) of patient undergoing angioplasty of the left anterior descending coronary artery. During the 60 seconds of balloon inflation ST elevation developed in the electrogram and to a lesser extent in the electrocardiogram accompanied by shortening of monophasic action potential duration. $\odot$
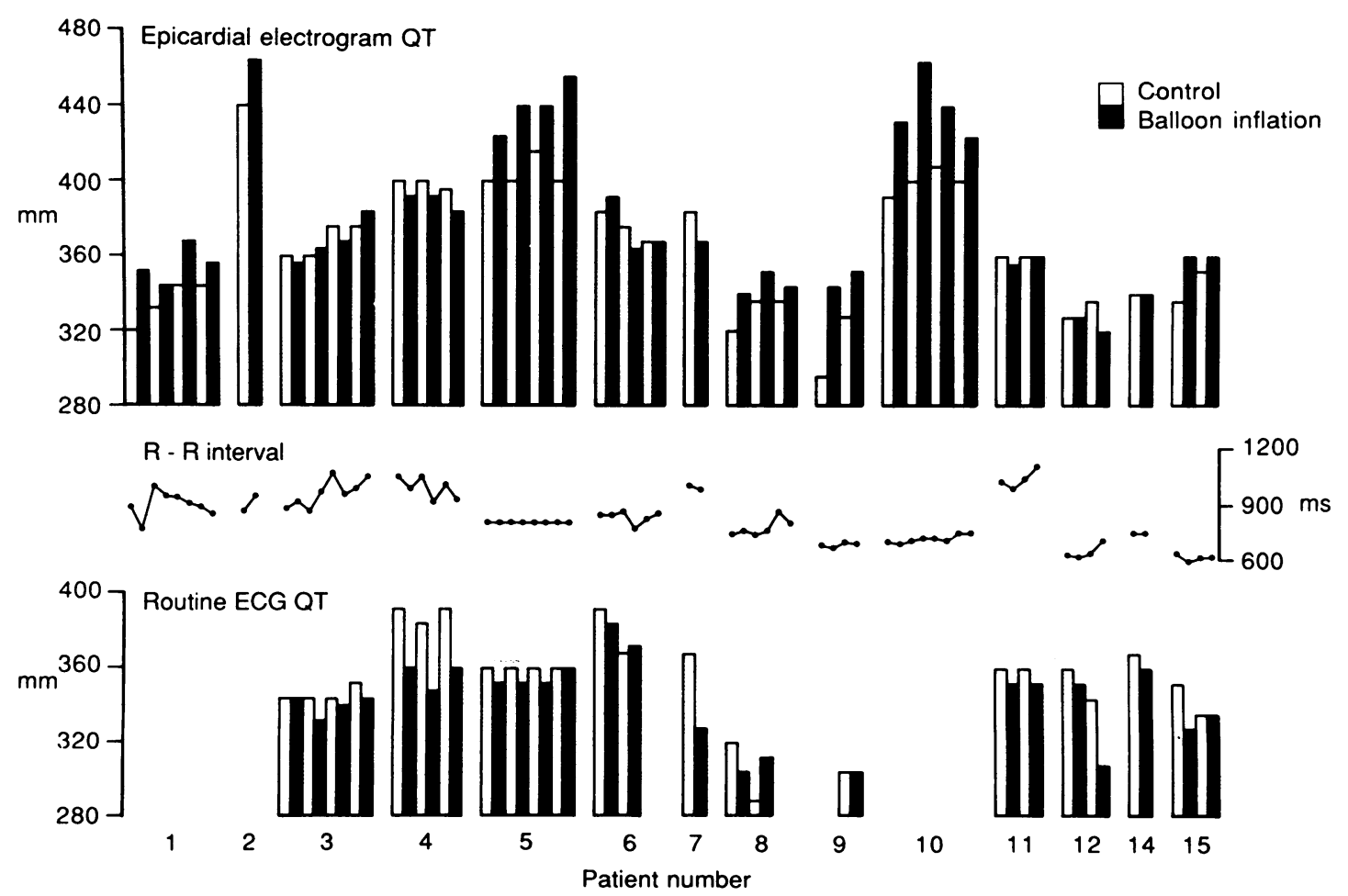

Fig $5 Q T$ interval in the epicardial electrogram (top) and routine electrocardiogram (ECG) (bottom) in patients undergoing angioplasty of the left anterior descending (patients 1-12) and circumflex (patients 13-15) coronary arteries. $V$ alues were recorded with the deflated balloon in position across the lesion (control) and at 60 seconds balloon inflation. The respective $R R$ intervals are shown in the centre panel. 
Table 2 Change in $Q T$ interval in the electrogram and electrocardiogram (ECG) during angioplasty at 60 s balloon inflation compared with control in two groups

\begin{tabular}{llll}
\hline $\begin{array}{l}\Delta R R \text { interval } \\
\text { between control } \\
\text { and 60 salloon } \\
\text { occlusion }\end{array}$ & $\begin{array}{l}Q T \text { interval } \\
\text { change }\end{array}$ & Electrogram & $E C G$ \\
\hline & Prolongation & 14 & 1 \\
$<20 \mathrm{~ms}$ & $\begin{array}{l}\text { No change } \\
\text { Shortening }\end{array}$ & 2 & 3 \\
& & $\mathrm{n}=17 / 36$ & $\mathrm{n}=12 / 24$ \\
& Prolongation & 18 & 1 \\
& No change & 3 & 4 \\
& Shortening & 4 & 10 \\
& & $\mathrm{n}=25 / 36$ & $\mathrm{n}=15 / 24$ \\
\hline
\end{tabular}

Occasions where the $R R$ interval changed by $<20 \mathrm{~ms}$ (top) and by $<40 \mathrm{~ms}$ (bottom) are presented. Thirty six patients had measurable QT intervals in the electrogram whereas only in 24 was QT measurable in the electrocardiogram. Of the 36 patients only 17 showed $R R$ interval changes of $<20 \mathrm{~ms}$ during the procedure of which only 12 had measurable QT changes in the electrocardiogran. A further eight patients showed changes in the RR interval of between 20 and $40 \mathrm{~ms}$ of whom only three had measurable QT intervals in the electrocardiogram.

no change, with the mean normalised monophasic action potential duration at 60 seconds inflation being $100.4(1.2) \%$ of control. In patients undergoing angioplasty of the right coronary artery only minimal changes in monophasic action potential duration were seen, the mean value at 60 seconds occlusion being $99.6(1.5) \%$ of control. In the patients undergoing angioplasty of the left anterior descending coronary artery, 19 of the total of 25 inflations showed shortening of the monophasic action potential of $<5 \%$, five showed shortening of between 5 and $10 \%$, and one showed a shortening of $16.4 \%$.

Figure 4 shows an example of shortening of the monophasic action potential duration associated with ST elevation in the electrogram.

\section{QT INTERVAL}

Figure 5 shows the QT interval of the electrogram

Table 3 ST segment elevation in the epicardial electrogram ( $\mathrm{mm}$ ) with the deflated balloon in situ before dilatation (left of each arrow) and at the end of successive inflations (right of each arrow) still with the deflated balloon in situ

\begin{tabular}{lllll}
\hline Good result & & \multicolumn{2}{l}{ Moderate result } \\
\cline { 1 - 2 } & $C-$ & & $C+$ & $C-$ \\
\hline $0 \rightarrow 0$ & $2 \rightarrow 1.5$ & & $1 \rightarrow 0.5$ & $1.5 \rightarrow 2.4$ \\
$0 \rightarrow 0$ & $0.2 \rightarrow 0.2$ & & $0 \rightarrow 0.8$ & $1.4 \rightarrow 0.8$ \\
$3.5 \rightarrow 0$ & $2.5 \rightarrow 1$ & & $0 \rightarrow 0$ & \\
& $3.5 \rightarrow 0.5$ & & \\
& $0.5 \rightarrow 0$ & & \\
& $0.5 \rightarrow 0.5$ & & \\
& $5.4 \rightarrow 0.6$ & & \\
\hline
\end{tabular}

$\mathrm{C}+$, angiographic evidence of good collateral supply;

C-, no angiographic evidence of collateral supply.
Table $4 S T$ shift ( $\mathrm{mm}$ ) in the electrogram (EG) and electrocardiogram (ECG) at 60 s balloon inflation during antioplasty (mean (SD))

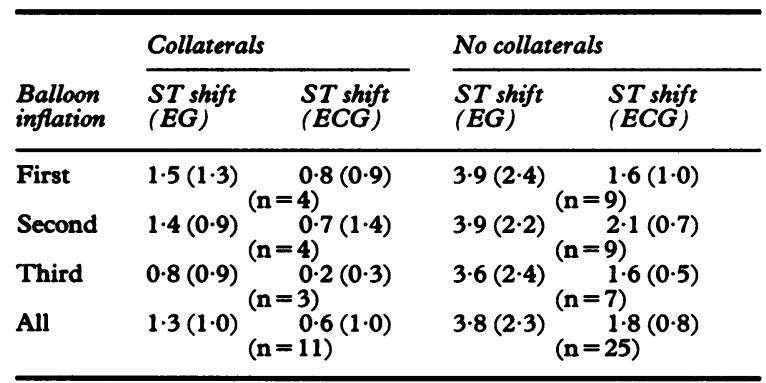

Data are given separately for first, second, third, and all inflations and subdivided into those patients with angiographic evidence of collaterals and those without.

and routine electrocardiogram. We were able to measure the QT interval satisfactorily in 36 balloon inflations in the electrogram and in 24 of these occasions in the electrocardiogram. In the one patient in this group who was paced (patient 5) the QT interval in the electrogram consistently lengthened during successive balloon occlusions whereas in the electrocardiogram there was progressive shortening of the QT interval. A similar disparity was seen between the QT interval in the electrogram and electrocardiogram on the occasions when only minimal changes in cycle length occurred (table 2 ).

\section{CORRELATION WITH ANGIOGRAPHIC EVIDENCE}

OF THE DEVELOPMENT OF COLLATERALS

Figure 2 and table 1 show the angiographic evidence of collateral blood flow to the area of myocardium normally supplied by the vessel undergoing angioplasty. Six of the 15 patients showed clear evidence of the development of collaterals to the compromised area of myocardium. The ST segment elevation in both the electrogram and the electrocardiogram was considerably less pronounced in those patients with evidence of the development of collaterals than in those without. The size of the change in the electrogram was twice that in the electrocardiogram (table 4). Furthermore, the initial ST elevation in the electrogram was less pronounced when the deflated balloon was in place across the stenosis before the first balloon inflation in those patients with well developed collaterals than in those without (table 3 ).

\section{CORRELATION WITH THE RESULT OF THE} PROCEDURE

Ten of the 15 patients undergoing angiography of the left system were classified as having a good angiographic result and five as having a moderate result (table 2, fig 2). Table 4 shows that patients with a high initial ST elevation in whom a good result was 

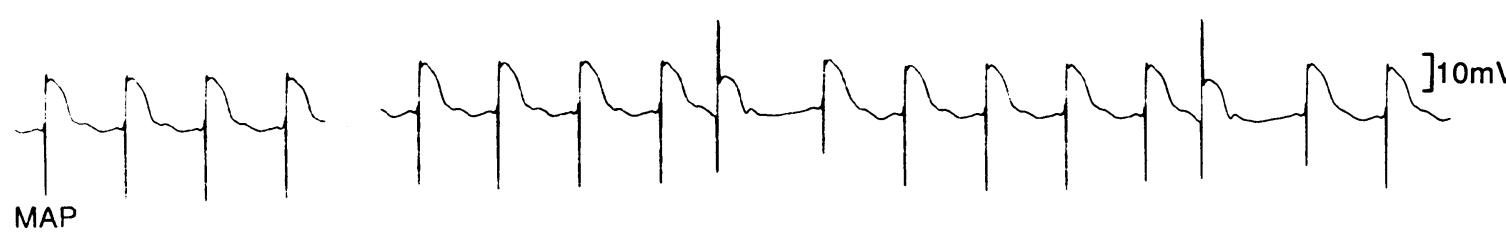

MAP

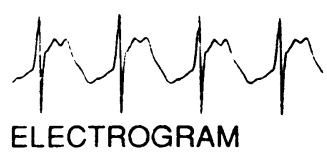

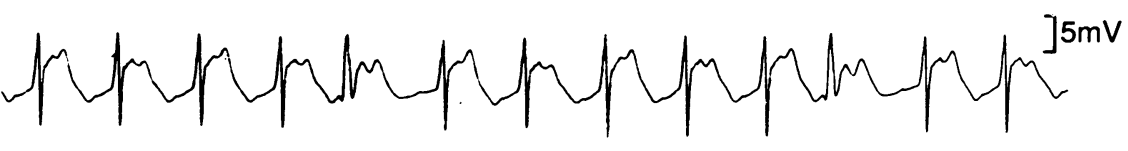

$$
\stackrel{500 \mathrm{~ms}}{500}
$$

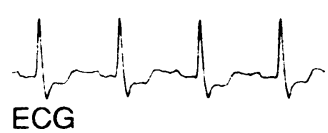

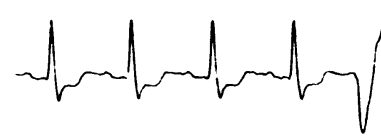<smiles>CCCCCCCCCCCCCCC</smiles><smiles>CCCCCCCC</smiles>

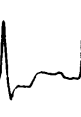

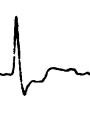<smiles>CCCCCCCCCCCCCC</smiles>

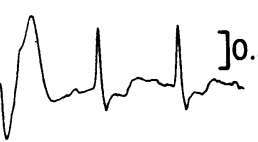

Fig 6 Patient undergoing angioplasty of the left anterior descending coronary artery. At 60 seconds of balloon occlusion $S T / T$ alternans was seen in the electrogram which was not evident in the electrocardiogram (ECG). Ventricular extrasystoles
developed and became frequent at this time. "Humps" at the end of repolarisation in the monophasic action potential (MAP) signal may be early after-depolarisations.

achieved tended to show a substantial fall in this elevation by the end of the procedure.

\section{ALTERNANS}

One patient (case 10) undergoing angioplasty of the left anterior descending coronary artery developed $T$ wave alternans which was obvious on the electrogram but not apparent in the electrocardiogram (fig 6). The alternans developed after 45 seconds of balloon occlusion and ceased after about 10 seconds of balloon deflation. During this period there were frequent ventricular extrasystoles.

\section{Discussion}

We found that ST changes on the guide wire electrogram during angioplasty are more obvious than those in the electrocardiogram and more sensitive to changes occurring in the area of myocardium being reperfused. This is to be expected in view of the wider angle subtended at the recording site for the electrogram, which is only a few millimetres away from the myocardium whereas the electrocardiogram electrode is more remote. However, this is not always the case and sometimes the reverse occurs. A possible explanation may be that solid angle theory applies to a point source whereas the guide wire is a continuum of several centimetres which may overlie areas of well perfused myocardium. This could be especially so when there is a good development of collaterals. A further possibility is that the guide wire may overlie scar tissue that is less likely to respond electrically. 0 This suggestion was made by Friedman et al to응 explain the lack of any discernible shift in the ST segment in the four patients they studied undergoingo angioplasty for distal right coronary artery disease. ${ }^{10}$ We also saw little change in our six patients under $\frac{\mathbb{}}{\Omega}$ going angioplasty of the right coronary artery, which suggests that it is unlikely that nearly all patients undergoing angioplasty for right vessel coronary artery disease have scar tissue close to the guide wire? however, only two of the patients under study for the left system did not show ST changes. We therefored suggest an alternative explanation: that the fat separating the right coronary artery from the 3 myocardium may act as an insulator. Cancellation isi an alternative possibility. Whatever model of the electrocardiographic waveform is considered, the waveform is essentially the algebraic sum of multiple potential differences throughout the myocardium $\frac{}{2}$ Owing to the spatial orientation of the conduction sequence across the ventricles the recording elec -0$)$ trode will usually record several positive and negativo potential differences. If the algebraic sum of these is zero during the inscription of the ST segment then $\omega$ the isoelectric line will not shift. We consider this unlikely because we often found that an extrasystolet with its different spatial orientation to the wire hade no influence on the electrogram recorded from the right coronary artery. If cancellation were a major factor then the altered vector would be expected to modify significantly the configuration of the elec- $\frac{\Omega}{\otimes}$ trogram. 
Measurements of the QT interval in the electrogram showed little correlation with the electrocardiogram; this is not unexpected because the angles subtended at the respective electrode recording sites are very different. Some of these differences may be due to the known patchy nature of ischaemia and localised differences in collateral response. It is also difficult to analyse the small changes in QT interval because the heart rate in the patients, who were not paced, was variable. We agree that rate correction of the QT interval is inappropriate and may be misleading. ${ }^{13-15}$ Bazett's correction, ${ }^{16}$ and other formulas $^{17}$ are intended to compensate for physiological variation in heart rate. However, the relation between QT interval and heart rate depends not only on the instantaneous interval between beats but also upon the variation in the heart rate during the preceding 2-3 minutes. ${ }^{15}$ In addition it is affected by other factors such as autonomic tone. ${ }^{18}$ The QT interval is known to increase in ischaemia owing to increased dispersion of action potentials. In most patients in whom the heart rate was steady during the sequence of balloon occlusion the QT interval was prolonged although this was not inevitably the case. This again is possibly because of differences in local microcirculatory tone.

Recordings of monophasic action potential correlated with the repolarisation phase of the underlying transmembrane potential. ${ }^{19-21}$ Changes in action potential duration are a sensitive index of the early electrophysiological changes produced by regional myocardial ischaemia. The monophasic action potential characteristically records electrical events occurring within a radius of $2-3 \mathrm{~mm} .^{212}$ This localised nature of the recordings is one of the main advantages of monophasic action potential recordings over electrograms and electrocardiograms. Though the monophasic action potential recording was close to the area of intervention in most patients the monophasic action potential did not register any ischaemic change. This indicates the limited extent of the ischaemia during the 60 second angioplasty occlusion.

The localised zone of initial ischaemia also accords with the relatively greater ST shift seen in the electrogram than in the electrocardiogram. Angiographic evidence of the development of collaterals seemed to influence the ST segment in the electrogram.

When the deflated balloon was positioned across the stenosis ST elevation was often seen in the electrogram in those patients without evidence of the development of collaterals, but there was little or no ST elevation when collaterals were present, except in one patient. The presence of collaterals seemed to lessen the degree of ST elevation in the electrogram associated with balloon inflation. After angioplasty

when the deflated balloon was still in position across the stenosis we often saw residual ST elevation in patients with no evidence of collaterals but it was usually only slight when collaterals were present.

Undoubtedly, the relative sizes of the deflated balloon and the patent diameter of the stenotic areas will have influenced the above results. After angioplasty these relative sizes will be more disparate in patients with a good result than in patients with a moderate result. Residual ST elevation was less pronounced in patients with a good result than in patients with a moderate result (table 3 ).

In one patient $T$ wave alternans developed that was obvious in the electrogram but not seen in the electrocardiogram or monophasic action potential (fig 6); this shows that alternans can be a local phenomenon and can be silent in the electrocardiogram. It is reasonable to assume that the alternans of the $T$ wave in this patient reflects alternating local differences in action potential duration. Alternans has been shown to be arrhythmogenic in the presence of ischaemia by various mechanisms including triggered activity and re-entry. ${ }^{23} 24$ In our patient ventricular extrasystoles were common when alternans was present but not in its absence. The truly local nature of this alternans is highlighted by the persistence of the sequence of changes in $T$ wave amplitude when ventricular extrasystoles intrude and the activation vector is altered.

We conclude that in patients undergoing angioplasty the electrophysiological changes occurring within the myocardium during a 60 second balloon inflation sequence are usually very localised. These changes are thereby more obvious in an electrogram recorded directly from the area than in the more distantly placed electrocardiogram. The signals obtained from the right coronary artery are of low voltage and do not yield a useful record unlike those from the left system. The usual absence of changes in the monophasic action potential when the recording electrode was in the area supplied by the vessel undergoing angioplasty further emphasises the very local nature of the ischaemic changes. The local nature of the electrogram signal is further supported by the presence in one patient of electrical alternans that was silent in the electrocardiogram and monophasic action potential. The QT interval in the electrogram did not correlate with the QT interval in the electrocardiogram. The resting ST segment in the electrogram and the shift associated with balloon inflation seemed to be influenced by angiographic evidence of collaterals. Finally, the intracoronary electrogram in the left system provides useful access for the electrophysiological recording of early ischaemic events, which may be useful in certain patients during angioplasty and may have a research application. 
We thank Paula Cupitt and the staff of the cardiac catheterisation laboratory for their help and the Middlesex Hospital Trustees for financial support (PT).

\section{References}

1 Burchell HB. Did Einthoven invent a string galvanometer? Br Heart J 1987;57:190-3.

2 Krikler DM. Electrocardiography then and now: where next? Br Heart J 1987;57:113-7.

3 Lazzara R, El-Sherif M, Scherlag BJ. Early and late effects of coronary artery occlusion on canine Purkinje fibres. Circ Res 1974;35:391-9.

4 Holland RP, Arnsdorf MF. Solid angle theory and the electrocardiogram: physiologic and quantitative interpretations. Prog Cardiovasc Dis 1977;19:431-57.

5 Spach MS, Barr RC, Lanning CF, Tucek PC. Origin of the body surface QRS and T wave potentials from epicardial potential distributions in the intact chimpanzee. Circulation 1976;55:268-78.

6 Taggart P, Sutton P, Runnalls $M$, et al. Use of monophasic action potential recordings during routine coronary artery bypass surgery as an index of localised myocardial ischaemia. Lancet 1986;i:1462-4.

7 Franz MR, Flaherty JT, Platia EV, Bulkley BH, Weisfeldt ML. Localisation of regional myocardial ischaemia by recording monophasic action potentials. Circulation 1984;69:593-604.

8 Donaldson RM, Taggart P, Bennett JG, Rickards AF. Study of electrophysiological ischaemic events during coronary angioplasty. Texas Heart $J$ 1984;11:24-30.

9 Taggart P, Sutton PMI, Hayward R, Emanuel RW, Swanton RH. Epicardial electrogram during angioplasty [Abstract]. Br Heart J 1988;59:133-4.

10 Meier B, Rutishauser W. Coronary pacing during percutaneous transluminal coronary angioplasty. Circulation 1985;71:557-61.

11 Friedman PL, Shook TL, Kirshenbaum JM, Selwyn AP, Ganz P. Value of intracoronary electrocardiogram to monitor myocardial ischaemia during percutaneous transluminal coronary angioplasty. Circulation 1986;74:330-9.

12 Taggart P, Sutton PMI, John R, Hayward R, Runnals ME, Swanton RH. Epicardial electrogram during successive balloon occlusion during percutaneoustransluminal coronary angioplasty [Abstract]. $B$ Heart J 1989;61:84.

13 Ward DE, Camm AJ. Q-T interval syndromes. Lance 1988;ii:47-8.

14 Lau CP, Freedman AR, Fleming S, Malik M, Camn $A J, W$ ard DE. Hysteresis of the ventricular paced $Q T$ interval in response to abrupt changes in pacing rate Cardiovasc Res 1988;22:67-72.

15 Seed WA, Noble MIM, Oldershaw P, et al. Relation of human cardiac action potential duration to the intervat between beats: implications for the validity of rate $\vec{\omega}$ corrected QT interval (QTc). Br Heart J 1987;57? 32-7.

16 Bazett HC. An analysis of the time relationship of electrocardiograms. Heart 1920;7:353-70.

17 Sarma JSM, Venkataraman K, Samant DR, Gadgit UG. Effect of propranolol on the QT intervals of normal individuals during exercise: a new method foo studying interventions. Br Heart $J$ 1988;60:434-9.

18 Browne KP, Zipes DP, Heger JJ, Prystowsky EN Influence of the autonomic nervous system on the QTO interval in man. Am J Cardiol 1982;50:1099-103.

19 Hoffman BF, Cranefield PF, Lepeschkin D, Surawicz B, Herlich HC. Comparison of cardiac monophasied action potentials recorded by intracellular and suction electrodes. Am J Physiol 1959;196:1297-301.

20 Franz MR, Burkhoff D, Spurgeon H, Weisfeldt ML, Lakatta EG. In vitro validation of a new cardiad catheter technique for recording monophasic actions potentials. Eur Heart $J$ 1986;7:34-41.

21 Blake K, Clusin WT, Franz MR, Smith NA. Mechan o ism of depolarization in the ischaemic dog hearto discrepancy between $T-Q$ potentials and potassium $P$ accumulation. J Physiol (Lond) 1988;397:307-30.

22 Levine JH, Guarnieri T, Kadish AH, White RI Calkins H, Kan JS. Myocardial repolarisation changesin patients undergoing balloon valvuloplasty. evidence of contraction-excitation feedback in man Circulation 1988;77:72-7.

23 Lab MJ. Contraction excitation feedback in myocar-dium: physiological basis and clinical relevance. Circo Res 1982;50:757-66.

24 Dilly SG, Lab MJ. Electrophysiological alternans and restitution during acute regional ischaemia in myocar- -3 dium of anaesthetized pig. $J$ Physiol (Lond) 1988;402:315-33. 